\title{
REPERCUSSÕES DA TERAPIA COMUNITÁRIA NO COTIDIANO DE SEUS PARTICIPANTES*
}

\author{
REPERCUSSIONS OF COMMUNITY THERAPY IN THE DAILY OF YOUR PARTICIPANTS*
}

\section{LAS REPERCUSIONES DE LA TERAPIA COMUNITARIA EN EL COTIDIANO DE SUS PARTICIPANTES*}

\section{Fernanda Jorge Guimarães ${ }^{1}$, Maria de Oliveira Ferreira Filha ${ }^{2}$}

RESUMO: A reforma psiquiátrica brasileira tem apontado para um modelo de saúde de base comunitária, buscando atender a demanda de pessoas em situação de sofrimento emocional. No Brasil, a Terapia Comunitária (TC) vem sendo utilizada como tecnologia de cuidado de superação do sofrimento, favorecendo o fortalecimento e/ou a construção de vínculos, bem como de redes sociais. A partir do projeto de extensão do Departamento de Enfermagem de Saúde Pública e Psiquiatria da Universidade Federal da Paraíba, emergiu este estudo que objetivou conhecer as repercussões da Terapia Comunitária no cotidiano das pessoas, moradores da comunidade Ambulante, no Bairro de Mangabeira/ João Pessoa/ Paraíba/ Brasil. Utilizouse o método de história oral temática, fazendo uso da técnica de entrevista para a coleta de dados, com nove participantes do grupo da Terapia Comunitária. Analisando o material empírico, identificou-se que os motivos que levaram os colaboradores a participar do grupo de TC foram: o convite feito pela equipe de saúde da família e a necessidade das pessoas em verbalizar as angústias e sofrimentos do cotidiano. As mudanças ocorridas no cotidiano dos colaboradores estão voltadas para uma maior compreensão de si e do outro e para a capacidade de transformação pessoal e social, bem como no fortalecimento dos vínculos: familiar, de amizade e espiritual. Destaca-se a construção dos vínculos de lazer, social e comunitário, a partir dos encontros de TC. Isto foi evidenciado pela conformação da rede de apoio social, a partir da mobilização dos participantes em busca de uma melhor qualidade de vida para si e para a comunidade. Consideramos que a TC se consolida como uma tecnologia de cuidado, que pode ser viabilizada pelas equipes de saúde da família, para a promoção da saúde, prevenção do sofrimento psíquico, fortalecimento de vínculos com a comunidade, construção de redes de apoio e inclusão social.

PALAVRAS-CHAVE: Terapia; Comunidade; Saúde mental.

ABSTRACT: The Brazilian psychiatric reform has been appearing as a model of health of community base, looking for the assistance of the people's demand in emotional suffering. In Brazil, the Community Therapy (CT) has been used as technology of care of prevention suffering, favoring the invigoration and/or construction of entails, as well as of social nets. Starting from the project of extension of the Department of Nursing of Public
Health and Psychiatry of the Federal University of Paraíba, this study aimed to know the repercussions of the Community Therapy in the daily of the people emerged, the Ambulante community's residents, of Mangabeira/ João Pessoa/ Paraíba/ Brazil. The method of thematic oral history was used, making use of the interview technique for the collection of data, with nine participants of the group of the Community Therapy. Analyzing the empiric material, we identified that the reasons that took the collaborators to participate in the group of CT were: the invitation done by the team of Family Health Program and the people's need in verbalizing the anguishes and sufferings of the daily. The changes happened in the daily of the collaborators came back for a larger understanding from itself and of the other and for the capacity of personal and social transformation, as well as in the invigoration of the entails: family, friendship and spiritual. We also stands out the construction of the entails of leisure, social and community, starting from the encounters of CT. This was evidenced by the conformation of the net of social support, starting from the participants' mobilization in search of a better life quality for itself and for the community. We considered that the CT consolidates as a care technology, that it can be made possible by the teams of health of the family for the promotion of the health in a general way, prevention of the psychic suffering, invigoration of entails with the community, construction of support nets and social inclusion.

KEYWORDS: Therapy. Community. Mental health

\footnotetext{
* Trabalho realizado a partir de Dissertação de Mestrado em Enfermagem, na área de concentração em Saúde Pública, do Programa de Pós-Graduação em Enfermagem do Centro de Ciências da Saúde (CCS) da Universidade Federal da Paraíba (UFPB) - João Pessoa, PB.

Enfermeira. Aluna do Programa de Pós-Graduação em Enfermagem- Mestrado, do Centro de Ciências da Saúde, da Universidade Federal da Paraíba (UFPB)- João Pessoa- PB. Bolsista CNPq. E-mail: ferjorgui2004@yahoo.com.br

Professora Doutora do Programa de Pós-Graduação em Enfermagem e do Departamento de Enfermagem Saúde Pública e Psiquiatria do Centro de Ciências da Saúde da Universidade Federal da Paraíba (UFPB). Terapeuta Comunitária. Membro do Grupo de Enfermeiras Experts no Ensino de Enfermagem em Saúde Mental das Américas. OPS/ OMS. João Pessoa/PB. E-mail: marfilha@yahoo.com.br
} 
RESUMEN: La reforma psiquiátrica brasileña, ha estado apareciendo como modelo de salud de base de la comunidad, buscado auxiliar la demanda de las personas con sufrimiento emocional. En Brasil, la Terapia Comunitaria (TC) se ha usado como la tecnología de cuidado para el sufrimiento, favoreciendo el fortalecimiento y/ o construcción de vinculaciones, así como de redes sociales. A partir del proyecto de extensión del Departamento de Enfermería de Salud Pública y Psiquiatría de la Universidad Federal de Paraíba, este estudio apuntó a conocer las repercusiones de la Terapia Comunitaria en el cotidiano de las personas residentes de la comunidad de Ambulantes, de Mangabeira / João Pessoa / Paraíba / Brasil. El método de historia oral temática fue usado, haciendo uso de la técnica de la entrevista para la colección de datos, con nueve participantes del grupo de la Terapia Comunitaria. Analizando el material empírico, identificamos que las razones de los colaboradores para participar en el grupo de TC fueron: la invitación hecha por el equipo de salud de la familia y la necesidad de las personas verbalizando las

\section{UM ITINERÁRIO DE PROCURA}

Com as transformações que afetam a sociedade atual, observa-se um aumento da criminalidade, a competição entre as pessoas em busca de espaços na sociedade, a desintegração social, o maior interesse por rituais religiosos, gerando uma sobrecarga de problemas emocionais e sociais que vêm modificando os valores e a conduta humana.

Os estudos de revelam que o espírito competitivo estimulado pelo capitalismo diminui a importância de formas tradicionais de comunidade, como família e vizinhança, criando situações de solidão, desenvolvendo frustrações, enfraquecendo os vínculos, espalhando agressividade e gerando sentimentos de abandono, insegurança e baixa autoestima. (KONDER, 2004). Além disso, o desemprego, a miséria, a fome, a migração, a privação da saúde e da educação, contribuem para a marginalização e a exclusão de pessoas da sociedade, bem como para o enfraquecimento dos vínculos de solidariedade.

A desagregação social e a perda da identidade cultural repercutem nos indivíduos, provocando somatizações que interferem no cotidiano e, muitas vezes, dificultam a realização de pequenas tarefas ou papéis sociais, chegando a manifestarem-se de modo incontrolável. (ANDRADE, 2003).

Por cotidiano, entende-se aquilo que se faz habitualmente, todos os dias. Os gestos, as ações corriqueiras, a linguagem, percebidos como triviais, podendo vir a ser julgados sem valor, contudo, eles são influenciados e influenciam a cultura da família, da vizinhança e da comunidade e, geralmente, estão presentes nos processos de cura e de adoecimento. (NASCIMENTO, 1995). angustias y sufrimientos. Los cambios ocurridos en la vida de los colaboradores implicaron en una comprensión más grande de sí mismo y del otro y para la capacidad de transformación personal y social, así como en el revigoramiento de las vinculaciones: la familia, la amistad y lo espiritual. Se destaca la construcción de vinculaciones de esparcimiento, social y de comunidad, empezando con los encuentros de TC. Esto se evidenció por la estructura de la red de apoyo social, empezando con la movilización de los participantes en busca de una calidad de vida buena para sí mismo y para la comunidad. Nosotros consideramos que la TC se consolida como una tecnología del cuidado, que puede hacerse posible por los equipos de salud de la familia para la promoción de la salud de una manera general, la prevención del sufrimiento psíquico, el revigoramiento de vinculaciones con la comunidad, la construcción de redes de apoyo y la inclusión social.

PALABRAS-CLAVE: Terapia. Comunidad. Salud mental.

O cotidiano dos brasileiros é marcado por problemas e sofrimentos que acarretam danos à sua saúde, de um modo geral. Estudos na área de saúde mental revelam que, no Brasil, $12 \%$ da população necessitam de algum atendimento, seja ele contínuo ou eventual; $6 \%$ apresentam transtornos psiquiátricos graves decorrentes do uso de álcool e de outras drogas e $3 \%$ sofrem com transtornos mentais severos e persistentes (BRASIL, 2005). Tanto a, Organização Mundial da Saúde - OMS, como a Organização PanAmericana da Saúde - OPS, entendem que a maioria desses transtornos são preveníveis e que devem ser encarados como prioridade política dos governos, para se evitarem mais danos à saúde das pessoas.

No cenário brasileiro, as áreas de saúde coletiva e saúde mental, vivem um período de transição entre dois modelos de cuidado: o de enfoque individual, curativo, discriminador e excludente e o outro cujo eixo é o coletivo, valoriza a promoção da saúde e a prevenção do adoecimento. Esse último busca a inclusão, a tolerância e a coexistência com a diferença e a diversidade. A pessoa é estimulada a ser agente da sua própria saúde e da saúde da comunidade que integra. Essa transição foi fortemente marcada nas décadas de 1980 e 1990, com os Movimentos da Reforma Sanitária e da Reforma Psiquiátrica. (MEDEIROS, 2005).

Com a Reforma Psiquiátrica, os serviços de saúde mental, não hospitalares, tornaram-se uma necessidade, para promover a ruptura com o modelo hospitalocêntrico e assegurar uma política de reabilitação e inclusão social. A promoção da saúde e a prevenção do adoecimento não são ações estratégicas específicas dos serviços de saúde mental não hospitalares, estando à preocupação com esta temática nas Unidades de Saúde da Família 
(USF's), que desenvolvem ações de prevenção do sofrimento emocional.

Nesse contexto a Estratégia Saúde da Família tem um importante papel a desempenhar, pois as Equipes de Saúde da Família (ESF) devem estar preparadas para promover a saúde mental no contexto geral da saúde, prevenir o adoecimento mental, identificando situações e fatores de risco e que provocam o sofrimento como também responder de modo satisfatório as necessidades de saúde da população.

Ainda são poucos os municípios que apresentam experiências de trabalho com grupos, cuja finalidade seja a promoção da saúde e prevenção do adoecimento, bem como o acompanhamento de egressos das internações, e a reabilitação e inclusão social. (MEDEIROS, 2005). Faz-se necessário incentivar novas propostas de serviços comunitários no processo de Reforma Psiquiátrica.

Nessa direção a Terapia Comunitária (TC) vem se consolidando como uma estratégia de promoção da saúde mental e prevenção de doenças e as equipes de Saúde da Família podem utilizar esse recurso como ferramenta em suas ações preventivas.

A Terapia Comunitária é uma prática de efeito terapêutico, destinada à prevenção na área da saúde e a atender grupos heterogêneos, de organização informal, num contato face-a-face e que demonstra um interesse comum que é o alívio de seus sofrimentos e a busca de bem-estar. Acrescenta-se que ela promove a construção de vínculos solidários criando-se uma rede de apoio social, reforçando os vínculos e evitando a desintegração social, onde a comunidade busca resolver os problemas que estão ao alcance da coletividade (FUKUI, 2004).

No Brasil, a Terapia Comunitária, vem sendo desenvolvida na Comunidade do Pirambu/ Fortaleza/ Ceará, para atender a demanda de pessoas em situação de sofrimento emocional. Hoje, de acordo com BARRETO (2005), a TC está presente em 27 estados brasileiros, com 16 Pólos Formadores e de Multiplicação e cerca de 7500 terapeutas comunitários formados.

A experiência com a TC, se deu a partir do desenvolvimento do projeto de extensão denominado Terapia Comunitária: uma ação básica em saúde mental, na comunidade Ambulantes no bairro de Mangabeira, motivando-nos para a realização deste estudo.

Assim, objetivou-se por meio deste estudo explicitar os motivos que levaram as pessoas da comunidade a participar da Terapia Comunitária; revelar as mudanças que ocorreram no cotidiano dos participantes da Terapia e identificar os vínculos formados e/ ou fortalecidos, nas pessoas e na comunidade, a partir dos encontros de Terapia Comunitária.

\section{O CAMINHO PERCORRIDO}

O delineamento do estudo foi feito com base nos pressupostos da História Oral Temática, que parte de um assunto preestabelecido, comprometendo-se com o esclarecimento ou opinião do entrevistador sobre algum evento definido. (MEIHY, 2005)

A pesquisa de campo foi realizada no conjunto habitacional Mangabeira IV, município de João Pessoa - Paraíba/Brasil, onde se realizam os encontros semanais de Terapia Comunitária. O conjunto de Mangabeira é constituído por sete subconjuntos, localizando-se na porção sudeste do município de João Pessoa. Foi inaugurado em 1983, para atender a demanda por moradia, de migrantes de pequenas cidades do interior do Estado, geralmente, do agreste e sertão paraibanos, assim como de outros Estados. Mangabeira é conjunto habitacional mais populoso da capital, onde reside uma população de 73.037 habitantes, constituída principalmente por trabalhadores assalariados de baixa renda. Mangabeira era um pedaço de chão coberto por árvores frutíferas como a mangaba, fruta pequena, chamada pelos índios de "coisa boa de comer", muito usada na preparação de sucos, doces e sorvetes.

Por meio do sistema de saúde, a comunidade é atendida nos diferentes níveis de atenção, tendo a sua disposição Unidades de Saúde da Família, ambulatórios, maternidade, e laboratórios. O Conjunto possui outros serviços: escolas, igrejas, associações de moradores, ONGs, comércio diversificado, clubes, correios, serviços jurídicos e policiais.

A Terapia Comunitária ocorre todas as quartas feiras, na Associação de Moradores, em parceria com a Equipe de Saúde da Família Ambulantes IV, pertencente ao Distrito Sanitário III, do município de João Pessoa.

No grupo de Terapia Comunitária participam em média 20 a 25 pessoas por encontro, cuja faixa etária predominante é de adultos jovens, em sua maioria mulheres, entretanto, há participações significativas de idosos crianças e adolescentes.

A definição da colônia se dá por padrões gerais da comunidade de destino, isto é, dados os traços preponderantes que ligam a trajetória de pessoas. A colônia é o grupo amplo, da qual a rede é a parte menor, ou seja, a rede é uma subdivisão da colônia que visa a estabelecer parâmetros para decidir sobre quem deve ser entrevistado ou não. (MEIHY, 2005).

A colônia, neste estudo, foi constituída pelos participantes dos encontros de Terapia Comunitária, sendo a rede formada pelas pessoas que atenderam aos seguintes critérios: freqüentam os encontros da TC desde a sua formação, tem participação efetiva nas mobilizações sociais, possuem maior envolvimento com a comunidade e demonstraram interesse em participar do estudo. Dessa forma, foram convidados nove colaboradores, que constituíram a rede, por melhor atenderem aos 
critérios acima, observando os aspectos éticos da pesquisa com seres humanos como preconizado pela resolução 196/96 do Conselho Nacional de Saúde que dispõe sobre as diretrizes e normas regulamentadoras de pesquisa envolvendo seres humanos.

Para a coleta de dados, foi utilizada a técnica de entrevista, com uso de gravador, realizada, tanto na Unidade de Saúde da Família Ambulantes, quanto no próprio domicilio do colaborador, conforme sua preferência e disponibilidade, sendo informado sobre os objetivos do estudo, suas etapas e sobre a importância de sua participação.

Os colaboradores receberam nomes fictícios para garantir-lhes o anonimato: Rubi, Esmeralda, Jade, Diamante, Zirconia, Turmalina, Safira, Ametista e Topázio. Esses nomes foram escolhidos, uma vez que têm certa similaridade com traços característicos do modo de ser de cada colaborador. Foi na aproximação com cada um deles, a partir dos encontros da Terapia Comunitária, que essa apreensão ocorreu.

A análise do material foi guiada pelo tom vital e as expressões fortes que surgiram das narrativas sendo procedido por um diálogo iluminado pelos autores que compõem a literatura pertinente.

\section{RESULTADOS E DISCUSSÃO}

Para compreender as falas dos colaboradores, mergulhou-se no texto tentando revelar a visão de mundo de cada um. O Tom vital, a leitura e o estudo do material empírico levaram a formulação e identificação de temas que foram captados no significado das palavras, gestos e falas. Dessa forma, organizou-se os tons vitais de acordo com os temas evidenciados, procurando atender aos objetivos propostos pelo estudo.

O grupo dos colaboradores deste estudo se caracteriza por pertencerem, predominantemente, ao grupo de idosos, aposentados, casados, tendo como ocupação atividades de grupos religiosos e artesanais. Tais características são importantes para melhor compreendermos suas falas e suas concepções sobre a Terapia Comunitária.

\section{Despertando para a existência pessoal: eu caçador de mim}

Verifica-se que os colaboradores relataram mudanças pessoais na relação consigo próprio e na relação com outras pessoas significativas em suas vidas. Assim, a compreensão de si e do outro e o potencial transformador foram as mudanças mais significativas presentes nas falas dos colaboradores, como indicam os seguintes depoimentos:

"A Terapia tem contribuído para me ajudar a fazer mais amizades, me acalmou, me ajudou a escutar, olhar mais o outro e olhar mais para mim e ver como sou. Eu estou tentando melhorar para dar o melhor de mim para os outros" (RUBI).

"A Terapia tem ajudado a me achar bonita, me amar, não esperar que os outros olhem para mim... Não ter vergonha de mostrar o que está sentindo... valorizar mais as pessoas, dar valor as minhas atitudes, tudo isso aprendi na terapia" (ESMERALDA).

Os discursos de Rubi e Esmeralda revelam uma auto-estima relacionada com a imagem que elas desenvolveram sobre si mesmas, por meio do processo de resiliência e empoderamento, onde ganharam habilidades e confiança para atuar sobre elas mesmas. Com o incremento do poder sobre si, conseguiram mudar a percepção que tinham de si mesma, do outro e da realidade onde vivem. Quando o indivíduo percebe a existência do outro há a possibilidade de aplicar suas habilidades, suas competências e descobrir a alteridade. (BARRETO, 2005).

Os colaboradores conseguiram, então, desenvolver um sentimento de pertença, especialmente quando conseguem expressar seus sentimentos no grupo. O sentimento de pertença favorece a formação de grupos, bem como é o responsável por sua manutenção, introduzindo elementos na fala, nos gestos presentes no agir cotidiano da comunidade.

A capacidade de superar as dificuldades possibilita aos indivíduos construírem um corpo de conhecimento e suscitar suas habilidades e recursos que os tornam especialistas naquele problema. Essa capacidade lhes conferem o poder de decidir sobre suas vidas, de se organizarem socialmente e de mobilizarem os recursos necessários para garantir acesso aos direitos básicos à uma vida com dignidade.

Portanto, em suas histórias, os colaboradores deixam evidente que são responsáveis por sua própria vida, elevaram sua autodeterminação, têm autonomia para tomar as próprias decisões e desenvolveram habilidades, compreensão e consciência sobre os aspectos de suas vidas.

A partir de dispositivos de ajuda mútua, podese desenvolver atividades e iniciativas de cuidado e suporte concreto na vida cotidiana, como o cuidado informal ao outro, ajuda nas tarefas diárias, entre outras. A ajuda mútua fornece apoio aos indivíduos na resolução de seus problemas, estabelece uma rede de amizade, que contribui de maneira positiva na construção da auto-imagem e eleva a auto-estima (VASCONCELOS, 2003).

A auto-estima é uma experiência íntima que reside no cerne do ser humano, é a soma da autoconfiança com o auto-respeito. Representa o componente emocional do eu, sendo um recurso importante para mudanças. (BRANDEN, 1995). O conceito que se tem de si é importante para que o indivíduo viva bem e feliz. Pessoas que possuem um bom conceito de si confiam mais em suas potencialidades e conseguem superar com mais 
facilidade as dificuldades para atingir seus objetivos enquanto que pessoas que possuem baixa autoestima sentem-se infelizes e inseguras.

$\mathrm{O}$ autoconhecimento deve ser estimulado, pois convida à reflexão a respeito da necessidade de cuidar de si, de amar-se, para poder cuidar do outro. Essa compreensão favorece o conhecimento de potencialidades e capacidade geradora de soluções. Percebe-se nesse movimento que se é capaz de resolver os problemas vivenciados no cotidiano, tidos anteriormente como insolúveis, uma vez que as reações a esses problemas são determinadas pela percepção que o indivíduo tem de si mesmo. Desenvolver a auto-estima é desenvolver a convicção de que se é capaz de viver e de ser merecedor da felicidade (REIKDAL \& MAFTUM, 2006).

Tal entendimento influencia escolhas, decisões e determina o tipo de vida que se quer construir (BRANDEN, 1995). A colaboradora Rubi relata:

"Após a Terapia, minha auto-estima melhorou..."

É interessante notar que a definição de seu autoconceito melhorou a partir dos encontros de Terapia Comunitária. Os colaboradores demonstraram que não necessitam da opinião de outros, pois possuem um autoconceito livre de críticas e repressão.

Evidencia-se que os participantes da Terapia Comunitária, descobrem 0 seu potencial transformador e a partir dessa descoberta começam a enxergar mudanças no comportamento e atitudes, como relatam Safira, Ametista e Diamante:

"Eu era mais aperreada, rebelde, malcriada, qualquer coisinha eu queria me estourar... mas hoje não! Hoje se acontecer qualquer coisa eu não vou chorar, não vou ficar "trancada", vou sair! Vou à casa de uma amiga, "espairecer" e não vou mais ficar trancada chorando o dia todo! Essa parte desapareceu de cima de mim..." (SAFIRA) "Eu era muito calada, mal conversava com as pessoas... depois que entrei na terapia, fiquei mais desenrolada para falar $e$ conversar... melhorou muito a minha vida... já aprendi muita coisa... quando saio de lá já volto com outro aspecto!" (AMETISTA)

"Eu era agressivo e hoje não sou mais. Eu quero tranqüilidade... ...É um lugar onde a gente se "aquece", se conhece melhor, aprende a respeitar o outro, saber tratar, saber compreender as coisas... Para mim é bom demais! A terapia para mim é uma amabilidade..." (DIAMANTE)

Nas falas de Diamante, Safira e Ametista a Terapia Comunitária modificou 0 modo de se relacionar com o outro, de se comunicar. A agressividade na fala aponta para uma maneira de lidar com as situações difíceis, percebidas como um fator que afasta as pessoas, mas não como um ato de violência física.
Destaca-se alguns fatores que dificultam o processo de comunicação evidenciados nas falas dos colaboradores. Dentre eles enfatiza-se os fatores pessoais, como a expressão facial, o movimento corporal, o contato olho no olho, os fatores sociais, como os valores, crenças e normas sociais, fatores fisiológicos, de personalidade e psicológicos. Entretanto, percebe-se que os colaboradores elaboraram suas próprias estratégias para lidar com tal situação, favorecendo o relacionamento interpessoal.

Portanto, a partir das estratégias elaboradas, a comunicação tornou-se, uma arte de bem gerir as mensagens, enviadas e recebidas, durante 0 processo de interação com o outro. Mas não é apenas a transmissão de mensagens que irá influenciar na comunicação eficiente. O tempo, o espaço, o meio físico envolvente, o clima relacional, o corpo, os fatores históricos da vida pessoal e social de cada indivíduo presente, as expectativas e os sistemas de conhecimento que moldam a estrutura cognitiva de cada ator social condicionam e determinam o "jogo" relacional dos seres humanos (DIAS, 2006). A comunicação, então, se tornou o intercâmbio de informação entre os sujeitos.

\section{A busca de sociabilidade e inclusão}

Verifica-se que em algumas histórias emergiram os motivos que levaram os colaboradores a permanecer freqüentando o grupo de Terapia Comunitária. Percebe-se o surgimento de sentimentos, percepções e necessidades atendidas que refletem uma busca pela sociabilidade, traduzida em atividades físicas e culturais, no prazer de conviver com outros para perceberem-se como parte de um contexto e não se sentirem excluídos socialmente, melhorando sua qualidade de vida. Durante os encontros de Terapia Comunitária cada pessoa aprende a encontrar o que necessita, como revelam os colaboradores a seguir:

"É na terapia que a gente descontrai, brinca, faz os exercícios e, graças a Deus, tem dado muito certo!" (JADE)

"Todo mundo tem que fazer a terapia na vida, sair um pouco, se distrair, viver melhor... até agora eu só posso dizer que está sendo ótimo!" (ZIRCÔNIA)

"É bom demais, porque a gente partilha os nossos problemas que a gente tem e percebemos que eles são mínimos, diante de outros" (ESMERALDA).

O padrão de sociabilidade brasileira se apóia no gregário, no lúdico, pouco individualizado em torno de valores de convivência. O lazer, as brincadeiras, as atividades físicas consistem em um referencial onde cada membro da comunidade se baseia para pensar, avaliar e discernir valores (CHAUÍ, 1986).

Vale destacar ainda que, nos encontros de TC a sociabilidade é estimulada pelas atividades 
culturais, onde há o resgate da cultura popular por meio de brincadeiras, contos, músicas, ditos populares, valorizando o saber de cada um. A cultura popular se caracteriza por um conjunto de práticas, representações e formas de consciência que possuem lógica própria. "A cultura traduz os desejos e anseios do ser humano" (CHAUí, 1986, p.25).

Tais práticas, representações, formas de consciência, idéias, hábitos e técnicas que existem atualmente e que constituem o arcabouço cultural que foi transmitido pelos antepassados e este transmitir de idéias e hábitos é freqüentemente apresentado como atributo puramente humano. (RALPH, 1981).

Dessa forma, quando se resgata a cultura popular, oferece-se oportunidade para o reconhecimento do ser humano como criatura gregária, com raízes históricas dos antepassados, desperta-se o verdadeiro sentimento de pertença e leva-se o grupo a fazer um contato com a continuação da sua existência.

\section{A formação do vínculo da identidade sócio- cultural}

A vinculação a terra, a comunidade são importantes para que o indivíduo se sinta parte integrante do sistema grupal, e assim, possa buscar meios para melhorar a sua vida e a vida da comunidade. Seria preciso resgatar de cada um a própria história pessoal, familiar, grupal e social, a solidariedade, a ajuda mútua para crescer com liberdade, responsabilidade e igualdade (SPÍNOLA 2001).

Nota-se que alguns colaboradores apresentavam vínculos frágeis e de risco, principalmente em relação à família e à comunidade a que pertencem. No entanto, suas histórias revelam que, a partir da participação e do engajamento no grupo de Terapia Comunitária, onde se descobriram como atores sociais, compreendendo seus potenciais de transformação pessoal e social houve o fortalecimento do vínculo familiar, vínculo de amizade e vínculo espiritual:

"A terapia melhorou muito, o vínculo com meu marido, no sentido de fazer reunião com a família quando uma coisa está errada..." (RUBI).

"Eu acho que a terapia cria uma oportunidade para você ter um diálogo mais aberto, para você saber conversar certas coisas e as experiências, vistas na terapia, você pode dar como exemplo. É uma porta aberta para cunhado, irmão..." (TURMALINA).

"Aprendi a dialogar com meu esposo, porque ele é muito fechado... estou sempre procurando o diálogo para a gente se compreender..." (ESMERALDA).

"Tenho melhorado bastante, porque dentro da terapia, me sinto melhor para conversar e para desabafar as coisas que estão me incomodando. Para mim ela trouxe uma maneira melhor de conversar com a família em casa, porque se eu estivesse na ignorância que eu sempre era..." (SAFIRA).

As expectativas em relação à família estão no imaginário coletivo, ainda impregnadas de idealizações. A maior expectativa é de que ela produza cuidados, proteção, aprendizado dos afetos, construção de identidades e vínculos relacionais de pertencimento, capazes de promover melhor qualidade de vida a seus membros e efetiva inclusão social na comunidade e sociedade em que vivem (CARVALHO, 2002).

Em Mangabeira, uma vez por mês, era escolhido algum tema e formado um grupo de discussão com a finalidade de aprofundar aquele tema através da literatura ou na fala de algum especialista. Em um desses encontros, foi escolhida a temática do relacionamento entre pais e filhos, o qual está sempre presente nos encontros de Terapia Comunitária.

Além do vínculo familiar, identificou-se que o vínculo de amizade foi fortalecido. Os discursos dos colaboradores trazem à tona a relevância da verdadeira amizade, como nos discursos a seguir:

"A diferença que tem de antes e depois da terapia, foi a de aumentar a minha amizade, me valorizar mais como ser humano, ver que os nossos problemas podem ser resolvidos. Nós sabemos resolver!" (ESMERALDA).

"Ah! Antes de participar da terapia eu não tinha as amizades que tenho hoje e por intermédio da terapia tenho muitas amizades boas" (AMETISTA).

Percebe-se na fala de Esmeralda, o empoderamento dos participantes na resolução de seus problemas do cotidiano. As pessoas da comunidade não são reféns das instituições ou dos profissionais, uma vez que aprenderam a valorizar o conhecimento e o saber que detém. A comunidade passa a agir, onde a família e as políticas sociais falham.

$\mathrm{Na}$ fala de Rubi, o vínculo de amizade se encontra frágil, mas com os participantes da Terapia Comunitária, ela sente confiança na relação estabelecida com os mesmos. $\mathrm{Na}$ terapia ela construiu novas amizades, com as quais pode contar, fortalecendo o vínculo de amizade. Experiência semelhante ocorreu com Esmeralda:

"Tenho amigas com quem posso desabafar, e elas são da terapia. A gente vai, umas procuram as outras, a gente continua... E se moramos perto, aí a gente conversa, desabafa, ela me dá uma sugestão, diz alguma coisa". (ESMERALDA)

No grupo, a interação entre os participantes favoreceu a construção de novos olhares para os diversos aspectos da vida do ser humano como, a espiritualidade, onde percebe-se em alguns relatos 
que ficou evidente o fortalecimento do vínculo espiritual:

"Na terapia sempre falam como é a vida... Sou católico... Eu ia uma vez por mês para a igreja. Hoje, vou todo domingo, porque aqui ensina a gente, que quanto mais a gente amar melhor. Esse é meu caso. Amo demais, gosto daqui e graças a Deus daqui não saio" (DIAMANTE).

"A terapia fortaleceu o que eu tenho, porque a gente vê pessoas voltadas para a igreja..." (RUBI)

"A terapia tem me ajudado a me confortar mais e fortificar mais a minha fé, porque com ela tenho me inspirado para ler o evangelho, a procurar entender melhor essas coisas, tem me influenciado muito com isso..." (SAFIRA).

Nos encontros de Terapia Comunitária há momentos de intensa espiritualidade, com orações, imposição de mãos, respeitando-se as crenças e os valores de cada um. Práticas de cura pelo toque e pela imposição das mãos humanas como instrumento terapêutico, têm sido usadas desde os primórdios da humanidade. Essa prática é comumente utilizada por "rezadores ou benzedeiros", muito respeitados em sua comunidade, onde exercem funções de cuidadores, parteiras, líderes comunitários. Tais práticas ainda são pouco utilizadas no sistema formal de saúde, em especial, na atenção básica (REIKDAL \& MAFTUM, 2006).

A espiritualidade ajuda ao homem em sua compreensão, indo a sua esfera mais profunda, transcendendo a sua realidade. A espiritualidade é tudo aquilo que produz uma mudança dentro do ser humano (BOFF, 2006). Ela impulsiona o ser humano para uma mudança interior, que se revela no cuidar ao outro, na solidariedade, na compreensão da vida. A espiritualidade é o campo onde se constrói o sentido da vida, de maneira simbólica. (VASCONCELOS, 2006).

Sendo uma das fontes de inspiração do novo, a espiritualidade gera um sentido pleno e de capacidade de autotranscendência do ser humano. Os portadores permanentes de espiritualidade são as pessoas consideradas comuns, que vivem a retidão da vida e o sentido de solidariedade. (BOFF, 2006).

A fé, emerge como uma força que ajuda a enfrentar problemas e tensões inerentes à vida. Atividades relacionadas à fé como grupos religiosos, dinâmicas de ajuda, conhecimento aprofundado do alvo da fé contribuem para a manutenção da saúde mental (REIKDAL \& MAFTUM, 2006).

No enfrentamento dos problemas vivenciados no cotidiano a fé, a crença em Deus é apontada como a estratégia mais presente, considerada muitas vezes a única ferramenta de resolução dificuldade vivenciada.

Pela preocupação em ajudar os outros, formam-se vínculos solidários e redes de apoio social que fortalecem o convívio comunitário. Quando se constroem as redes solidárias e se promove a vida, se consegue consolidar os vínculos saudáveis, reforçar os vínculos frágeis e combater os vínculos de risco.

Enquanto alguns vínculos se fortaleceram, outros foram construídos a partir dos encontros de Terapia Comunitária, como o vínculo comunitário, o vínculo de lazer e o vínculo social.

Geralmente, quando aparecem problemas estruturais, como a violência e a insegurança a comunidade tende a retrair-se da participação em atividades sociais, com medo de sofrer algum tipo de agressão. Todavia os participantes da TC discutem processos de mobilização para enfrentar o problema, formando-se uma rede invisível de apoio solidário àqueles que se sentem mais ameaçados. Percebe-se que a ajuda mútua contribuiu para que os participantes construíssem um novo olhar para a violência, onde não predomina o medo e o silêncio.

Partindo do exposto, ficou evidente a construção do vínculo comunitário. Essa construção se deu por meio dos encontros de Terapia Comunitária e da divulgação desta experiência com as pessoas da comunidade, onde os colaboradores estabeleceram uma maior interação com outros indivíduos, os quais não mantinham uma relação de intimidade, como na fala de Rubi:

"...Isso tem me aproximado mais das pessoas, dos vizinhos de outras ruas, que a gente nem conhece e termina conhecendo,... Tem criado um vínculo muito bom com a comunidade..." (RUBI)

A comunidade é uma unidade estruturada, organizada, de grupos, à qual o indivíduo pertence necessariamente. Pode-se pertencer a uma comunidade em conseqüência de necessidades externas ou internas, isto é, por meio de uma escolha individual (HELLER, 1992). Em alguns encontros da Terapia Comunitária, emergiram os motivos que levaram os participantes a escolherem a comunidade de Mangabeira para residirem, para pertencerem, como por exemplo, a presença de familiares e amigos no conjunto, muitas vezes relacionados a fatores econômicos, mas principalmente afetivos.

Participantes do grupo de Terapia Comunitária e os atores- colaboradores deste estudo se sentem integrados e felizes na comunidade onde moram, construindo, assim, um vínculo saudável. Quando o indivíduo se agrega a um grupo, a uma comunidade, não perde sua identidade, desenvolve sua autonomia e seu papel social. Tal compreensão ajuda no entendimento sobre as atividades de ocupação do tempo livre (atividades físicas, de lazer, diversão, culturais, ou de cuidado com o corpo e com a mente), uma vez que tais atividades, realizadas, geralmente em grupo, constituem-se em alternativa para que as pessoas retomem seus papéis sociais.

Nos encontros de Terapia Comunitária, os participantes são estimulados a desenvolver atividades de lazer. Em alguns momentos são os próprios participantes que se organizam com a 
finalidade de promover atividades de integração social, como as comemorações de datas especiais e passeios turísticos, que contribuem para a formação do vínculo de lazer e de amizade.

Alguns colaboradores criaram juntamente com a equipe do PSF, o Grupo de Idosos da comunidade. As atividades desenvolvidas se referem a trabalhos manuais, encontros de oração e atividades de lazer. Além disso, no grupo, os idosos são estimulados a cuidar da sua saúde, constituindo-se em um espaço de educação em saúde.

Safira é uma das participantes do grupo de idosos. Em sua fala, as reuniões de grupo são tidas como estratégia para enfrentar as dificuldades vivenciadas no cotidiano, como os conflitos familiares. O grupo se tornou um local, onde ela pode encontrar apoio e compreensão:

"Estou começando a participar do grupo de idosos daqui, participo da Terapia, Legião de Maria, grupo de idosos do Margarida Maria Alves. Eu me sinto bem, no meio deles. Me sinto alegre, feliz, porque em casa ás vezes só tem aborrecimento..." (SAFIRA).

A participação no grupo ajuda o individuo se sentir mais integrado, uma vez que o ser humano é um ser gregário, estando inserido num grupo. "Os grupos facilitam o exercício da autodeterminação e da independência, pois podem funcionar como rede de apoio que mobiliza as pessoas na busca de autonomia e sentido para a vida, na auto-estima, na melhora do senso de humor" (GARCIA et al, 2006, p.176). Esses aspectos são essenciais para ampliar a resiliência e diminuir a vulnerabilidade.

O vínculo é sempre um vínculo social, mesmo sendo com uma só pessoa (PICHON- RIVIÉRE ,2000). Por meio da relação com essa pessoa repetese uma história de vínculos determinados em um tempo e em espaços determinados. Por essa razão, o vínculo se relaciona com a noção de comunicação e aprendizagem.

A formação de vínculos permite a construção de redes de apoio social, que fortalecem a convivência na comunidade. Portanto, por meio da construção de redes de apoio social, verifica-se que há maior mobilização entre as pessoas, especialmente quando é necessário resolver situações- problema vivenciadas pela comunidade, buscando a utilização dos recursos disponíveis quer seja internamente ou externamente e que a troca de experiências gera um processo de crescimento e empoderamento, tanto individual como coletivamente.

\section{Terapia comunitária como espaço de fala, escuta e partilha}

Quando se procurou saber quais os motivos, interesses ou necessidades que levaram as pessoas a buscar a Terapia Comunitária, os discursos revelaram a existência de uma rede de comunicação entre a equipe de saúde da família e a comunidade.
Dentre os motivos destacados pelos colaboradores, foram ressaltados: os convites feitos oralmente pela equipe de saúde da família aos freqüentadores da Unidade de Saúde e a divulgação da TC na mídia local. Contudo, sabe-se que os membros da equipe de saúde da família já vinham identificando pessoas em situação de sofrimento emocional, que necessitavam de um espaço de escuta, para minimizar as suas angústias.

Como em todo sistema, a comunicação é importante e para que ele tenha vida faz-se necessário encontrar interlocutores que facilitem o repasse da mensagem. A comunicação verbal quando bem utilizada na comunidade pode seduzir as pessoas para um espaço de participação coletiva.

A comunicação é uma das mais básicas e vitais de todas as necessidades humanas. Os homens precisam se entender e cooperar uns com os outros. É por meio da comunicação interpessoal que podemos compreender melhor o outro, isto é, seu modo de pensar, sentir e agir (DIAS, 2006).

Ressalta-se que a parceria com a Equipe de Saúde da Família foi fundamental na implantação e divulgação da Terapia Comunitária na comunidade. Como já havia interesse tanto por parte da comunidade como da equipe em ter um espaço para escuta das necessidades da população do bairro, os Agentes Comunitários e a Enfermeira da equipe tornaram-se importantes atores nesse processo. As falas de Esmeralda, Safira e Diamante revelam essa afirmação:

"Eu não procurei a terapia, fiquei sabendo. $A$

Agente de Saúde me convidou, e eu vim" (ESMERALDA).

"Eu fiquei sabendo, porque sempre venho aqui no Posto e a Enfermeira e a Técnica de Enfermagem me convidaram para participar dessa reunião" (SAFIRA).

"Quem me indicou foi a Enfermeira do PSF, porque eu e minha esposa éramos daqui do Posto" (DIAMANTE).

Convém destacar a participação de alguns membros do grupo de Terapia Comunitária em programas de comunicação de massa, com o objetivo de divulgar essa experiência. Seu sucesso foi evidenciado pela mídia local, televisiva, que interessada, possibilitou, por mais de uma vez, a divulgação da atividade que ocorria semanalmente no bairro.

"Eu vi no jornal sobre a terapia, então me

deu vontade de participar..." (AMETISTA)

Outro motivo verbalizado pelos colaboradores foi a necessidade de comunicação - ter com quem falar sobre o sofrimento. Durante os encontros de Terapia Comunitária as pessoas se sentem escutadas, acolhidas, importantes e reconhecidas, o que se evidencia especialmente nas falas de Safira e Jade:

"Eu procurei a terapia para aliviar meu sofrimento e as dores que vem com a idade, porque vivo sempre em casa, sempre 
descontente, recebendo reclamação de uma coisa e outra..." (SAFIRA).

"Eu procurei a terapia para desabafar os problemas que tenho, sair mais tranqüila, sair melhor do que como estava... porque lá a gente tem com quem desabafar e tirar aquilo que está sentindo..." (JADE).

Quando uma pessoa se comunica com outra, está oferecendo uma definição de si mesma ao interlocutor e espera uma resposta. A resposta do interlocutor funciona como um espelho para a pessoa permitindo reconhecer-se. Portanto, quando as pessoas se comunicam adquirem uma maior consciência do seu próprio eu. A Terapia Comunitária é, portanto, uma rede viva de comunicações gestuais, onde cada pessoa pode expressar sentimentos quer seja de alegria, tristeza, medo, angústia, decepção, frustração. Nessa rede, a dor pode ser acolhida, partilhada e transmutada. É o Kaos, crise, transformando-se em Kairós, onde cada um resignifica seu sofrimento (BARRETO, 2005).

Os discursos das colaboradoras, acima apresentados, é a expressão do sentimento de solidão presente na vida das pessoas, especialmente as idosas, que habitam cidades grandes e que geralmente são migrantes, vindos do interior para a Capital. Nas cidades, estão fora do sistema de produção do mercado, perdem laços afetivos, sociais, familiares e o meio urbano não tem favorecido a vinculação da pessoa a terra. Perde-se o sentimento gregário de pertencimento e de enraizamento.

A sociedade dá muito valor à aceitação social, ou seja, o homem precisa relacionar-se com outras pessoas a fim de orientar-se. Se a pessoa é estimada, isto é, socialmente aceita, acredita-se que raramente esteja só (MAY, 1990). Se não consegue relacionar-se com outras pessoas de maneira satisfatória e saudável, o homem desenvolve a sensação de isolamento, de solidão e se sente vazio e amedrontado.

A solidão é uma característica do homem moderno. Em tempos onde a competição desenfreada e a falta de compaixão e solidariedade influenciam fortemente a vida das pessoas, agregarse a um grupo, faz com que o individuo se sinta socialmente aceito.

Em alguns relatos dos colaboradores emergiram determinados significados acerca da compreensão de Terapia Comunitária. Tais relatos apresentam a Terapia Comunitária como um espaço que favorece a partilha de experiências, demonstrando que a TC atende aos objetivos aos quais se propõe, como na falas abaixo:

"Terapia para mim é um espaço onde a gente pode colocar os problemas, vivenciar experiências de outras pessoas... No momento em que a gente vivencia aquelas experiências a gente... toma como lição e como exemplo! É um espaço de partilha onde se adquire muita experiência... Acho

\begin{abstract}
muito importante... gosto muito!" (TURMALINA).

"Saio da terapia novinha... Gosto muito de ir, me sinto bem no dia em que vou... Cada qual dá um testemunho, uma coisa diferente e a pessoa cada vez mais, vai melhorando... Conto aquilo tudo, então alivia mais um pouco..." (TOPÁZIO).
\end{abstract}

Através da troca de experiências, os participantes têm a seu dispor um espaço de escuta, acolhimento e fala dos seus problemas. Nesse momento estabelecem laços de afinidades com 0 outro. Além das ligações pelo sangue, outras ligações são impostas, por meio da convivência, da estima, da afinidade o que gera uma pluralidade em termos de solidariedade (NASCIMENTO, 1995).

Além dos laços de afinidade, a partilha de experiências permite que a comunidade construa seu próprio conhecimento. O conhecimento do dia-a-dia, o senso comum, que se funda no emocional, próprio da comunidade passa a ser valorizado. Diante do saber especializado, o senso comum é considerado como matéria bruta a ser trabalhada. Assim, a vida cotidiana vai se originando no pensamento e nas ações do homem comum. Levando-se em consideração o senso comum, não se está abdicando do intelecto, pelo contrário, busca-se uma melhor compreensão da realidade vivida por meio da junção entre o saber popular e o conhecimento científico.

O sofrimento é fonte de competência, um sofrer que torna o indivíduo mais humanizado e especialista em sua resolução. A partir das falas dos colaboradores, percebe-se que eles construíram um conhecimento a partir de suas vivências, de sua história pessoal de vida, que unidas ao conhecimento acadêmico contribui para o enfrentamento das inquietações do cotidiano.

Assim, o cotidiano não é reconhecido como algo rotineiro e destituído de sentido, sendo vivenciado como uma experiência radical do presente. Por isso, as estratégias de enfrentamento vão sendo construídas ao longo da trajetória de vida dos colaboradores.

$\mathrm{Na}$ comunidade, cenário deste estudo, os participantes do grupo de Terapia Comunitária, juntamente com a Associação de Moradores do conjunto, Equipe de Saúde da Família e profissionais liberais realizaram algumas mobilizações no sentido de promover a discussão dos problemas do conjunto, bem como estratégias para superá-los. Dessa forma, destacamos o "Dia D dos Jovens", Semana do Idoso, Oficina de Levantamento dos Problemas da Comunidade, Palestras Educativas sobre depressão, climatério, Oficina de dança.

Mediante a ação, os personagens desta história, homens e mulheres mostram quem são, revelam sua identidade pessoal e fazem sua aparição ao mundo, ou seja suas qualidades, talentos e defeitos estão implícitos em tudo o que esses homens e mulheres falem e façam. (ARENDT, 1993). 
O grupo de Terapia Comunitária é um sistema formado por vários subsistemas que se interrelacionam, formando uma rede complexa em que cada um influencia o outro a partir do compartilhamento das informações.

Nesse contexto, compreende-se o problema do indivíduo nas suas relações, nos vínculos estabelecidos, uma vez que o comportamento do mesmo repercute no grupo familiar e comunitário. Dessa forma, conclui-se que a circulação de informações nessa rede de relações contribuiu de maneira decisiva para o fortalecimento da comunidade do Conjunto Mangabeira IV Ambulantes.

\section{CONSIDERAÇÕES FINAIS}

A Terapia Comunitária se apresenta como uma tecnologia de cuidado que permite preencher essa lacuna, por meio do trabalho em grupo, de baixo custo e com ações de promoção da saúde mental e prevenção do sofrimento emocional para as comunidades, como também como uma estratégia de reabilitação e de inclusão social pela rede de apoio psicossocial que ela pode ajudar a construir.

Como instrumento de cuidado, a TC demonstrou atender aos princípios norteadores do SUS, ensinando-nos a construir redes de apoio social, possibilitando mudanças sociais e reconhecendo as competências de cada ator social para contribuir na superação das dificuldades.

Neste estudo, a análise do material empírico revelou que os motivos os quais levaram os participantes para os encontros de Terapia Comunitária foram a necessidade de se ter um espaço de convivência grupal e o convite feito por membros da equipe de Saúde da Família, em especial na figura da Enfermeira, que incentivava os clientes do posto de saúde para uma atividade grupal e de mobilização social, por meio de um sistema de comunicação social.

Nota-se que o que mantém essas pessoas participando dos encontros de TC é a possibilidade de serem ouvidas, de falar de suas angústias do cotidiano, suas preocupações que tiram o sono e a realização de atividades que favorecem a sociabilidade. Tudo isso apoiado em uma lógica de "estar junto à toa", com os membros do grupo se encontrando com a finalidade específica de compartilhar a paixão e os sentimentos, tendo como única razão a preocupação com um presente vivido coletivamente. (MAFFESOLI, 1998).

Dentre as mudanças que ocorreram no seu dia-a-dia, percebe-se que houve uma melhor compreensão de si e do outro. Os colaboradores perceberam que tem um valor, com um incremento na auto-estima, acreditando no seu potencial de transformação, a nível individual e comunitário.

Esse processo de transformação conseguiu fortalecer vínculos, tornando-os mais saudáveis com a família, o lazer, a espiritualidade e a construir novos vínculos a partir dos encontros de Terapia
Comunitária, como o vínculo de amizade, vínculo comunitário e o vínculo social.

As entrevistas suscitaram algumas compreensões acerca da Terapia Comunitária como um espaço de partilha das experiências vividas, onde seus participantes podem aliviar o seu sofrimento, evidenciando-se o processo resiliente, revelando, ainda, um incremento do poder sobre si mesmo, sobre a capacidade de gerenciar a própria vida, contribuindo para que o grupo se mobilizasse em torno de questões vividas coletivamente.

Portanto, este estudo vem também contribuir de maneira significativa para a prática do cuidado em saúde dos profissionais que se compromete com os princípios da Reforma Psiquiátrica, que buscam modelos de cuidado efetivos, que priorizam a aquisição de autonomia e capacidade de transformação social.

A Terapia Comunitária atende as metas a que se propõe e que deve ser divulgada como uma prática de caráter terapêutico, transformadora da realidade e que pode ser utilizada nos diversos níveis de atenção a saúde, especialmente na atenção básica.

Tendo em vista os resultados alcançados por esta investigação, recomenda-se $s$ a utilização da Terapia Comunitária, como tecnologia de cuidado na rede de atenção básica, pois, por meio dessa pesquisa, houve um maior envolvimento com a comunidade, bem como o reconhecimento da Terapia Comunitária como um instrumento de cuidado.

Os vínculos estabelecidos com a equipe de saúde permitiu o desenvolvimento de ações de proteção e promoção a saúde como as oficinas, encontros de jovens e grupos da terceira idade, melhorando $\mathrm{o}$ atendimento, tornando-o mais humanizado. A partir dos encontros de TC houve a construção de um espaço de socialização das estratégias de enfrentamento, de reflexão e autoconhecimento.

Espera-se que a partir desta investigação, exista uma maior divulgação da Terapia Comunitária como tecnologia de cuidado e como princípio norteador das ações de saúde e que se possa estimular as equipes de saúde, principalmente as equipes de saúde da família a absorver essa tecnologia social e pedagógica de saúde.

\section{REFERÊNCIAS BIBLIOGRÁFICAS}

ANDRADE, R.L.M.V. Dependência de benzodiazepínicos na Unidade de Saúde da Família Concórdia Pedras de Fogo. 2003. 42.f. Trabalho de Conclusão de Curso (Especialização em Saúde da Família)- Núcleo de Estudos em Saúde Coletiva Universidade Federal da Paraíba, João Pessoa,2003. ARENDT, H. La condición humana. Buenos Aires: Paidós Ibérica, 1993.

BARRETO, A.P. Terapia comunitária passo a passo. Fortaleza: Gráfica LCR, 2005. 
BOFF, L. Espiritualidade: um caminho de transformação. Rio de Janeiro: Sextante, 2006.

BRANDEN, N. Auto-estima: como aprender a gostar de si mesmo. 18. ed. São Paulo: Saraiva, 1995.

BRASIL. Ministério da Saúde. Secretaria de atenção à saúde. Políticas de Saúde Mental. [online] Disponível em: http://portal.saude.gov.br/portal/sas/mental/area.cfm?i $\mathrm{d}$ area $=851$ [Acesso em 10 de out. 2005].

CARVALHO, M.C.B. O lugar da família na política social. In: A família contemporânea em debate. 4. ed. São Paulo: Cortez, 2002.

CHAUÍ, M. Conformismo e resistência. São Paulo: Brasiliense, 1986.

DIAS,F.N. Barreiras à comunicação humana. [online] Disponível em: http://www.sociuslogia.com/artigos/barreira01.htm.

[Acesso em 10 de ago. 2006].

FUKUI, L. Terapia comunitária e o conceito de comunidade: uma contribuição da sociologia. [online] Disponível em: http://www.usp.br/nemge/textos tecendo estudando/t erapia comunidade fukui.pdf [Acesso em 02 de nov. 2004].

GARCIA, M.A.A et al. Atenção á saúde em grupos sob a perspectiva dos idosos. Revista Latinoamericana de enfermagem, v.14, n.2, p.175-182, 2006.

HELLER, A. O cotidiano e a história. 4.ed. São Paulo: Paz e Terra S/A, 1992.

KONDER, L. O que é dialética. São Paulo: Brasiliense, 2004.

MAFFESOLI, M. O Tempo das tribos: o declínio do individualismo nas sociedades de massa. 2.ed. Rio de Janeiro: Forense Universitária,1998.

MAY, R. O homem à procura de si mesmo. 16. ed. Petrópolis: Vozes, 1990.

MEDEIROS, S.N. Prevalência dos transtornos mentais e perfil sócio-econômico dos usuários atendidos nos serviços de saúde em municípios paraibanos. 2005. 119f. Dissertação (Mestrado em Enfermagem) - Centro de Ciências da Saúde, Universidade Federal da Paraíba, João Pessoa, 2005.

MEIHY, J.C.S.B. Manual de História Oral. 5 ed. São Paulo: Loyola, 2005.

NASCIMENTO, E.S. Compreendendo o quotidiano em saúde. Revista Enfermagem, v.2, n.4, p. 31-38, dez, 1995.

PICHON- RIVIÉRE. E. Teoria do vínculo. 6.ed. São Paulo: Martins Fontes, 2000.

RALPH, L. O homem: uma introdução à antropologia. Tradução Lavínia Vilela. 11ed. São Paulo: Martins Fontes, 1981.

REIKDAL, A. R.; MAFTUM, M.A. O cuidado com a saúde mental da equipe de enfermagem do PSF de uma unidade de saúde. Nursing, v.98, n.8, p.925-930, 2006.

SPÍNOLA, J.R.de Y.S. Grupos: em busca de uma nova convivência. In: THIERS, S. (org). A essência dos vínculos. Rio de Janeiro: Altos da Glória, 2001.
VASCONCELOS, E. M. O poder que brota da dor e da opressão: empowerment, sua história, teorias e estratégias. São Paulo: Paulus, 2003.

VASCONCELOS, E. M. A espiritualidade no trabalho em saúde. São Paulo: Hucitec, 2006.

Artigo recebido em 20.11.2006

Aprovado para publicação em 29.12.2006 